\title{
The Preliminary Discussion of Chinese Character Font Design
}

\author{
Bing Liu 1, a, Fan Wang 2,b, * \\ ${ }^{1}$ Academy of Fine Arts, Northeast Normal University, Changchun130024, China \\ a ice8515@163.com, b wangf06@163.com
}

Keywords: Chinese character font design, Font design, Formal beauty, Decorative beauty, Artistic conception beauty.

\begin{abstract}
Based on the frontier design theory, this paper deeply analyzes the formal beauty, decorative beauty and artistic conception beauty of Chinese character font design, and the design principles and techniques are studied. Combined with related theories, the author explains the creative thinking, cultural connotation, value orientation and aesthetic orientation of Chinese character font design; summarizes the new ideas and application methods, so as to provide some design ideas and inspiration for modern Chinese character font design. With the popularization of information and digital technology, Chinese character font design, precipitated profound cultural connotation and rich emotional implication, as one visual language of the world, is making positive contributions to global economic and cultural development.
\end{abstract}

\section{Introduction}

Chinese characters is by far the longest continuous use of the main character, is also the ancient period of the text system only spread to the present text, the China, with Chinese characters as the main official text. Chinese characters have developed to a high standard in ancient times, not only the use of China, for a long time also served as the only international exchange of East Asian text, before 20th Century, Chinese characters are Japan, Korea, Vietnam and other countries, the Ryukyu official written specification text, East Asian countries have a certain degree of self-creation Chinese characters [1-3].

The record symbol of Chinese characters is one of the oldest characters in the world, more than six thousand years of history. Chinese characters after thousands of years of evolution, gradually formed the "Seven body of Chinese characters": oracle bone script, bronze inscriptions, seal script, clerical script, cursive script, regular script, semi-cursive script. A Chinese character is a square word formed by strokes, so it is called the "square characters" $[4,5]$.

Chinese character font design in visual communication design field, is the design behavior of expressing text scheme in symbolic form, assume the role of information transmission and communication, its application not only expresses its literal meaning directly through abstract visual symbols, it is also a kind of artistic expression means to improve design grade, has certain aesthetic function, through the research and development of font design; contains a certain geographical, historical, cultural, economic accumulation, is a specific social and cultural psychological performance [6].

\section{Characteristics of Chinese character font design}

Chinese character font design, is the creation of fonts again, appropriate modeling changes, that can make the Chinese characters reach more ingenuity alone artistic effect. Modern Chinese font design becomes more abstract complex, with the most concise symbols to represent different profound meaning, so we can explore its profound meaning from three aspects of Chinese characters, that is formal beauty, decorative beauty and artistic conception beauty $[7,8]$.

Analysis on the formal beauty of Chinese character font design. Modern Chinese character font design needs to break through the general visual habits, should be in a simple, symbolic form, will make people easier to understand and remember. In the modern Chinese character font design in 
order to pursue the special effect, often the font structure of the stroke re modification and regular, trying to make Chinese characters show novel visual experience, causes to be rich readability and interesting. Diversified forms of Chinese characters, including the visual features, abstraction, and artistry and philosophical, in modern society, the extensive application of Chinese character design can play an important role in the dissemination and communication of cultural information. After the development of the times, Chinese characters are regarded as the most artistic kind of writing, with the high degree of neat beauty and order beauty.

Analysis on the decorative beauty of Chinese character font design. In visual art, decoration is most closely related to people, the decorative design of Chinese characters represents the process and development of history and culture. The unique style and connotation of Chinese characters, to give a pleasing feeling, and contains a long social and cultural heritage, to a certain extent, to meet the people's physiological, psychological and spiritual needs. The development of Chinese characters experienced a gradually developed as abstract symbol of the process by the image of the text drawing, rich in decorative meaning, with the development of human society, in different stages, decorative art contains different social and cultural connotations. When this kind of decorative art comes into people's life, some new problems will arise, there is only the surface decoration, dazzling, and ignore the meaning of it, gorgeous appearance can only be a flash in the pan; therefore, the real Chinese character design decoration art needs "inside" "outside" unifies, that simple pursuit of the surface of the flash is not enough, both to highlight the external temperament, but also to highlight its connotation.

Analysis on the artistic conception beauty of Chinese character font design. Chinese characters are the most representative of Oriental art, with a time-honored history; in contemporary design art also shows plenty of vitality. Abstract points, lines, faces, pens, paintings in Chinese characters seem to be tendons, bones, blood and meat in the body of life, the sublimation of its artistic realm conveys the feelings and thoughts of the nation. Whether it is information dissemination, or artistic creation, China's Chinese characters since ancient times is a metaphysical way of creation, the pursuit of meaning and ideas beyond the text information, it contains people's feelings of the outside world and their own moral standards. Chinese character is not only a text language; its shape is a unique visual plastic art, in thousands of years of development, cohesion of the Chinese nation infinite imagination. In the diversified development of world design, Chinese character font design must have its own characteristics, with Chinese unique concept; it is possible to have a place on the stage of international design.

\section{Principles and techniques of Chinese character font design}

Font is the expression of the author's ideas, but also with visual recognition of symbols, it can not only express concepts, but also convey information in a visual way. Chinese character font design is the product of human production and practice, with the development of human civilization and gradually matures, its inheritance, with the following four principles.

Cognitive ability. Font is created in the practice of production, the purpose is to convey some information, even after thousands of years of historical evolution, the structure of the word has been a breakthrough, but always keep reading graphic text. The basic purpose of font design is to better and effectively convey information, make the audience accept the accurate information efficiently.

Visual features. The font must be subject to design requirements based on, so that the font has a distinctive, unique personality, give people a wealth of visual experience, the visual nature of the font contains many aspects, such as language, image, structure and so on. Each word has its own visual tension and appeal, in addition to the basic reading function; font design is always combined with other graphic design, so as to show their charm. Font design clever, novel, unique, attractive, so that people have a good impression, and can get a good artistic and emotional experience.

Jumping characteristic. Font is a special symbol composed of points, lines, faces and strokes. In the arrangement and form of the structure, using symmetry, balance, contrast, rhythm and other aesthetic principles, design beautiful and harmonious text, is the important content of font design. On 
the font thickness line collocation, coordinate the relationship between strokes and strokes, grasp the font rhythm and dynamic, to give people the enjoyment of beauty, font design can make people gifted with an extraordinary retentive memory, the most important is the font of artistic appeal and visual impact, this will improve the effectiveness of information communication.

Graphic character combination. Six thousand years of development history, for the entire human culture provides a wealth of treasure, with the rapid development of social economy, the world has entered the information age; China has occupied a pivotal position in this era. Chinese character font design as a design form, with a profound cultural heritage and diversity of performance, therefore, in logo design, book design, packaging design, graphic design and other visual communication design field has been widely used. Chinese font design has made a great contribution to visual communication design, and has developed Chinese culture, pay attention to Chinese font design in the process of social development, and continue to promote its application in visual communication design is very necessary.

\section{Summary}

Chinese font design pays attention to the beauty of font form, which is a reflection of traditional ideas, but also the development trend of font design. Chinese characters unite the unique image thinking and aesthetic mentality of the Chinese nation, it is more profound and perfect than any other nation, the Chinese characters used in visual communication design, undoubtedly has great vitality and appeal. The essence of Chinese character font design is embodied in three aspects: " formal beauty", "decorative beauty" and "artistic conception beauty", Chinese character design from the divergent thinking, combined with cultural connotation and aesthetic taste, and through professional artistic aesthetic design approach, to form an excellent font design with artistic and cultural characteristics and value orientation. Chinese design has moved to the international market, Chinese designers should tap the potential of Chinese characters in the visual design function, make its form and technique richer, Chinese characters, this ancient and vital visual element, shine in the world in the field of design communication.

\section{Corresponding author}

Fan Wang, Professor, Northeast Normal University, CHINA, wangf06@163.com.

\section{Acknowledgements}

The author gratefully thanks the financial support by Research Project in National Social Science Foundation Art Project (14BG085) and Jilin Social Science Fund Project (2013BS14).

\section{References}

[1] Shouhui Zhao, Chinese Character Modernisation in the Digital Era: A Historical Perspective, Current Issues in Language Planning, Vol. 6 (2005), p. 315-378.

[2] Yanhui Zhang, Similarity and Degree of Perplexity Analysis of Chinese Characters, Journal of Quantitative Linguistics, Vol.18 (2011), p. 189-206.

[3] Liu Na, Yu Ruifeng, Zhang, Yunhong, Effects of Font Size, Stroke Width, and Character Complexity on the Legibility of Chinese Characters, Human Factors and Ergonomics in Manufacturing \& Service Industries, Vol. 26(2016), p. 381-392.

[4] WU Hao, QC Zhan, On the Application of Chinese Character Fonts Design in Packaging Design, Packaging Engineering, Vol. 30 (2009), p. 150-151.

[5] SB Lim, MS Kim, Oriental character font design by a structured composition of stroke elements, Computer-Aided Design, Vol. 27 (1995), p. 193-207. 
[6] YE Yunyun, Inheritance and Innovation of Traditional Chinese Characters Decoration: Practice of Font Design, Design Research, Vol. 2 (2012), p. 55-59.

[7] WD Wang, Chinese Character Design in the Deconstruction Logo, Packaging Engineering, Vol. 31 (2010), p. 113-116.

[8] LN Zhang, XM Zhang, XY Chen, The Legibility Research of Chinese Font and Font Structure, Chinese Journal of Ergonomics, Vol. 20 (2014), p. 32-37. 